\title{
Vitamin A Supplementation and Stunting Levels Among Two Year Olds in Kenya: Evidence from the 2008-09 Kenya Demographic and Health Survey
}

\author{
Elizabeth W. Kimani-Murage ${ }^{1, *}$, Crispin Ndedda ${ }^{2}$, Katherine Raleigh $^{3}$ and Peninah Masibo ${ }^{4}$ \\ ${ }^{1}$ African Population and Health Research Center (APHRC), Nairobi Kenya \\ ${ }^{2}$ Micronutrient Initiative, Nairobi Kenya \\ ${ }^{3}$ U.S. Agency for International Development (USAID), Nairobi, Kenya \\ ${ }^{4}$ Department of Epidemiology and Nutrition, School of Public Health, Moi University, Nairobi Campus, Nairobi \\ Kenya
}

\begin{abstract}
Background: High levels of undernutrition, particularly stunting, have persisted in Kenya, like in other developing countries. The relationship betweeen vitamin A supplementation and growth of children in Kenya has not been established, while there are context-specific variations on the relationship. This study explores this relationship in the Kenyan context.
\end{abstract}

Methods: The study uses data from the 2008-09 Kenya Demographic and Health Survey, involving children aged 2435 months, a weighted sample of 1029 children. Descriptive and logistic regression analyses were conducted. The outcome variable of interest is stunting, while the exposure variable of interest is ever receiving a dose of vitamin $A$ supplement. Secondary outcomes include underweight and wasting status.

Results: The prevalence of stunting in the study group was $46 \%$; underweight $20 \%$; and wasting $6 \%$. The prevalence of ever receiving vitamin A supplement was $78 \%$. Receiving vitamin A supplement was significantly negatively associated with stunting and underweight status, adjusting for other co-risk factors. The odds of stunting were $50 \%$ higher $(p=0.038)$, while for underweight were $75 \%$ higher $(p=0.013)$ among children who did not receive Vitamin $A$ supplement compared with those who did.

Conclusion: This study demonstrates that receiving vitamin A supplement may be beneficial to growth of young children in Kenya. However, though freely offered through immunization services to children 6-59 months, some children do not receive it, particularly after completing the immunization schedule. There is need to establish innovative and effective ways of maximizing utilization of this intervention, particularly for children who have completed their immunization schedule.

Keywords: Micronutrients, malnutrition, undernutrition, child growth, developing countries, public health interventions.

\section{INTRODUCTION}

Childhood undernutrition remains a pervasive public health problem in the developing countries. It is associated with adverse short-term and long-term effects. It is a serious risk factor for ill health, associated with increased morbidity and mortality, and contributes substantially to the burden of disease in the developing countries [1-3]. Undernutrition, particularly stunting is also associated with compromised cognitive development and future economic productivity; and higher risk of metabolic diseases later in the life course [4-6]. The Millennium Development Goals (MDGs) prioritize reduction in undernutrition worldwide, however, young children are often vulnerable to undernutrition and its consequences, including

*Address corresponding to this author at the African Population and Health Research Center, Nairobi, Kenya, P.O. Box 10787, 00100, Nairobi Kenya; Tel: +254-724322193; Fax: +254 (020) 4001101; E-mail: ekimani@aphrc.org, lizmurage@gmail.com stunting, underweight and wasting, which are prevalent in many low-income countries worldwide. In particular, estimates of stunting for children under the age of five are greatest in Africa, with East Africa carrying the highest burden, where close to $50 \%$ of young children in the region are afflicted [7]. In Kenya, the prevalence of stunting for children aged less than five years is $35 \%$ [8].

Infant and young child nutrition, including micronutrient supplementation, has gained much attention over the previous decades, in part due to an increase in the understanding of the health benefits of nutrition in the first 1000 days of life. Breastfeeding, supplemental feeding and micronutrient fortification practices can benefit the health of young children through improved immune system response and adequate protection against infections [9, 10]. Micronutrient deficiency, specifically vitamin A deficiency, is estimated to cause more than a half million deaths among children under age five [1]. It is 
clear that poor health conditions are the result of a multitude of factors including child nutrition and maternal and household characteristics [11]. The continued high prevalence of stunting, underweight, and wasting across East Africa, including Kenya, emphasizes the importance of distinguishing the specific determinants of poor health status. By fully identifying and understanding the key risk factors that influence child health, it is possible to guide national policy and to better meet the needs of children.

The focus of this study was to determine the potential effects of nutritional supplementation on the growth of children age 24-35 months in Kenya. Primarily, the effects of receiving vitamin $A$ supplements on stunting status was explored, and secondarily the effect on wasting and underweight status of young children, using data from the 2008-09 Demographic and Health Survey (DHS) in Kenya. Several studies have looked at micronutrient deficiencies and health status, showing the benefits of vitamin $A$, iron, zinc and calcium [9, 10, 12, 13]. However, other factors in different environmental contexts also influence growth of young children, including breastfeeding practices, parasitic infections and childhood diseases [14, 15]. This complexity has resulted in inconsistent results regarding the effects of vitamin A supplementation on child growth in developing countries [16-18] and indicates the need for context-specific studies.

Therefore, the study's goal was to better understand the relationship between vitamin A supplementation and growth of children in the Kenyan context. Children were evaluated for stunting as a key outcome of interest. The analyses had the overarching goal to address the burden of poor health and thus inform policy so that the negative cycle of poverty that poor health status perpetuates can be broken. The emphasis on alleviating this public health problem is critical in Kenya and throughout East Africa, and the long-term benefits of policy decisions and actions taken to improve the health of young children should be based on the key determinants of malnutrition.

\section{Conceptual Framework}

The conceptual framework (Figure 1), adapted from the UNICEF 1990 framework of causes of malnutrition [19] describes immediate and underlying causes of malnutrition. In this study, the focus was on the association of the immediate causes of malnutrition, specifically vitamin A supplementation, on nutritional status, particularly stunting, among children age two. The effects of other immediate factors including duration of breastfeeding, deworming and child morbidity, and other co-risk factors at the child, maternal and household levels were controlled for.

\section{DATA AND METHODS}

The study uses secondary data from the 2008-09 Kenya Demographic and Health Survey (KDHS). The Demographic and Health Surveys are nationally representative household surveys conducted in approximately 75 countries that provide data on a wide range of indicators including family planning, health and child nutrition. The 2008-09 KDHS was conducted

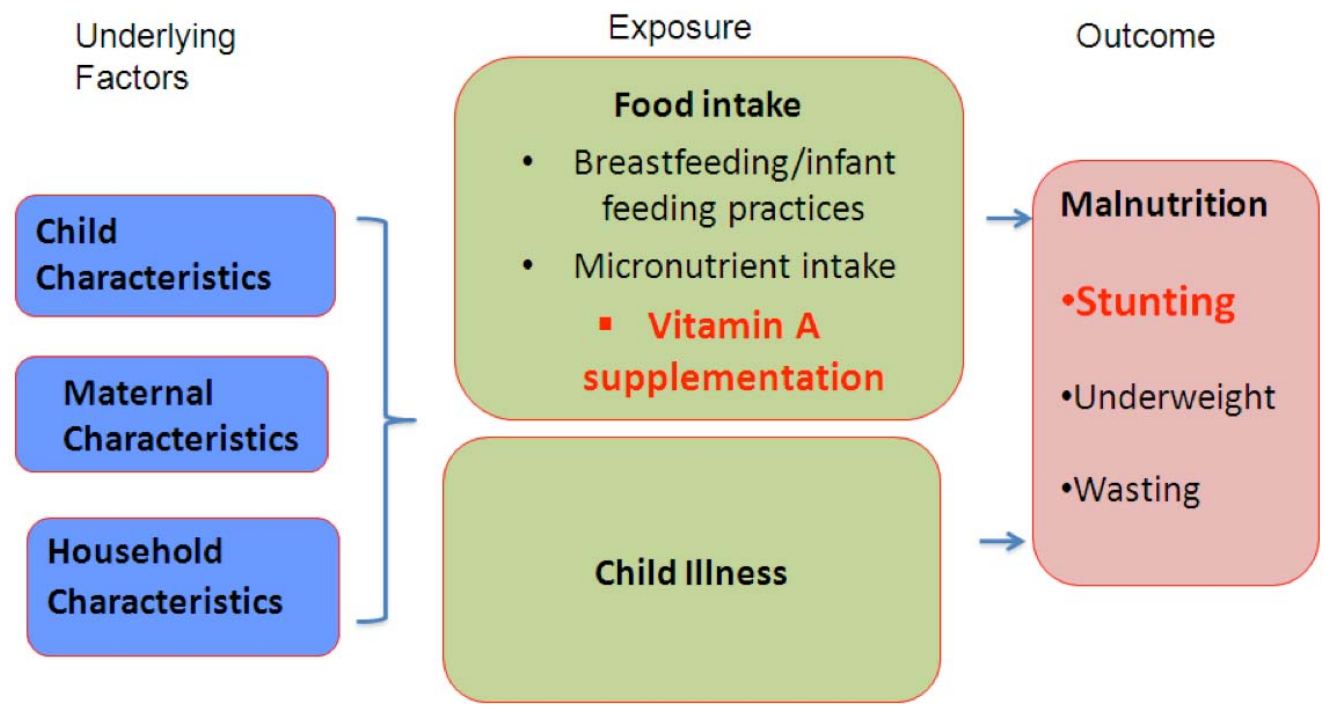

Figure 1: Immediate and underlying causes of malnutrition among children in Kenya. (Adapted from UNICEF's 1990 Framework of Causes of Malnutrition [19]). 
by the Kenya National Bureau of Statistics in collaboration with government and non-government institutions. It covered 9,057 interviewed households, in which 8,444 women were interviewed.

The KDHS adopts a two-stage sampling design. The first stage involves selection of data collection clusters (enumeration areas). The second stage involves the systematic sampling of households from an updated list of households in each cluster. Regions with low population density are over-sampled, while those with high population density are under-sampled. Sampling weights are later applied to the data to obtain a nationally representative sample. All women age 1549 who are either usual residents or visitors present in the households on the night before the survey are eligible to be interviewed in the survey.

This study analyzed data from the Kids Register (KR file). This file consists of records of interviewed de facto mothers (i.e. mothers who slept in the household the night before). Analysis involved children age 24-35 months whose anthropometric measurements (weight and height) were taken and were not considered erroneous (as detailed below). A sub-sample of 1,048 children age 24-35 months was filtered from the original sample of children aged below five years (unweighted $\mathrm{N}=6,079$ children). To obtain nationally representative estimates, sampling weights were used. The final weighted sample included a total of 1,029 children age 24-35 months.

\section{Anthropometric Measurements}

All children below age five had their weight and length/height measured. These anthropometric measurements were taken by trained teams, consisting of two interviewers and one health worker. Weight was measured to the nearest $0.1 \mathrm{~kg}$ using lightweight, bathroom-type scales with a digital screen designed and manufactured under the authority of UNICEF, and length/height was measured to the nearest $0.1 \mathrm{~cm}$ using a calibrated height board.

\section{Variables}

\section{Outcome Variables}

The outcome measures for this analysis include stunting, wasting and underweight, defined here as a height-for-age $z$-scores (HAZ), weight-for-height $z$ scores (WHZ) and weight-for-age z-scores (WAZ) less than -2. The HAZ, WHZ and WAZ were were generated using the World Health Organization's
(WHO) 2006 growth standards [20]. Children with HAZ and WAZ from -5 and below and WHZ -6 and below were excluded from the analysis as they were considered to be extreme or incorrect. A total of 20 such cases were excluded from the analysis. The outcome variables were coded as "not stunted"/"stunted", "not wasted"/"wasted" and "not underweight"/ "underweight" respectively.

\section{Explanatory Variables}

The key explanatory variable of interest was ever receiving vitamin $A$ supplement. The Kenyan government policy on vitamin A supplementation requires that the supplement be given to all children from the age of six months up to 59 months, at sixmonth intervals. The 2008-09 KDHS determined vitamin A supplementation status among these children through information from the caregivers as well as verification from documentation on the child health cards. For this variable, children who had ever received a dose of vitamin A supplement and those who have never received the supplement were coded as "Yes"/"No" respectively.

Other explanatory variables in the analysis include important risk factors for undernutrition classified as child, maternal and household factors, as described below.

\section{Child Factors}

Child's age was analyzed as a continuous variable; child's sex was coded as "Female" and "Male"; birth order was coded as $1^{\text {st }}, 2^{\text {nd }}, 3^{\text {rd }}, 4^{\text {th }}$ and above; child's birth size as perceived by the mother was coded as "Average", "Larger than average" and "Smaller than average"; deworming status in the six months preceding the survey was coded as "Yes"/"No"; duration of breastfeeding in months was used a continuous variable in the regression analysis but coded as "24+ months", "0-5 months", "6-11 months", "12-18 months" and "18-23 months" in the descriptive analysis; child morbidity as reported by the mother including acute diarrhoea, fever and cough within the previous 24 hours for fever or within the two weeks preceding the survey for diarrhoea and cough. These were coded as "No"/"Yes".

\section{Maternal Factors}

Maternal variables included the age at birth of the child, coded as "under 20", "20-24", "25-29", "30-34" and "35 and above"; marital status was coded as "In union" if married or cohabiting, and "Not in union" if 
never married, separated, divorced or widowed; maternal nutrition was measured by the body mass index -BMI, computed as weight in kilograms divided by the square of height in metres, and coded as "Normal BMl" (18.5-24.9), "Low BMl" $\left(<18.5 \mathrm{kgs} / \mathrm{m}^{2}\right)$ and "Overweight or obese" $\left(\mathrm{BMI} \geq 25 \mathrm{~kg} / \mathrm{m}^{2}\right)$. Pregnant mothers and those two months postpartum were placed in a separate category. Maternal education was coded as "Secondary and above", "No formal education", and "Primary"; work status was coded as "Not working currently" and "Working currently".

\section{Household Factors}

Household residence was coded as either rural or urban, while region was coded as Nairobi, Central, Coast, Eastern, Nyanza, Rift Valley, Western and North Eastern provinces. Household wealth index was used as an indicator of socioeconomic status based on household assets [21]. Each asset was assigned a factor score generated through principal components analysis. The resultant asset scores were standardized in relation to a normal distribution with a mean of zero and standard deviation of one. Each household was then assigned a score for each asset, and the scores were summed for each household. The wealth index was coded as "Lowest", "Lower", "Middle", "Higher" and "Highest". Other household factors included were: drinking water source, coded as "Improved" (including piped water, bottled water, tubewell/borehole and protected wells and springs) and "Unimproved" (including unprotected wells and springs, rain water and surface water sources); toilet facilities, coded as "Improved" (including water closets and ventilated improved pit latrines), "Unimproved" (including traditional pit latrines) and "No facilities" (including nontoilet faecal disposal methods mentioned in the survey such as bush and field); and number of children under age five living in the household, used as a continuous variable in the regression analysis but coded as "1", "2" and " 3 and above" in descriptive analysis. De facto children (children visiting the household at the time of the survey but who were not usual residents in the household $)(n=14)$ were assigned drinking water source and toilet facility of the host household. Additionally, they were assigned the number of children under age five that live with their mother.

\section{Statistical Analysis}

Data analysis was undertaken using Stata version 11.1. For bivariate analysis, Pearson's chi-square test was used to determine differences in proportions by background characteristics at the child, maternal and household levels. Multiple logistic regression was conducted with the outcome variables (stunting, underweight and wasting) and explanatory variables at the child, matenal and household levels as described above. A two-sided $p$-value of $<0.05$ was considered statistically significant. To account for the cluster sampling design, svyset commands in Stata were used, using pweights.

\section{RESULTS}

This study involves 1,029 children age 24-35 months, 488 girls (47\%) and 541 boys (53\%). The prevalence of stunting was the highest among the three nutritional indices, at $46 \%$; prevalence of underweight was $20 \%$; while prevalence of wasting was lowest, at $6 \%$. The prevalence of ever receiving a dose of vitamin A supplement in the study group was $78 \%$.

Table 1 shows the prevalence of stunting and other forms of malnutrition (underweight and wasting) by background characteristics for children age 24-35 months in Kenya. The results of the bivariate analysis indicate that ever receiving vitamin A supplement was significantly negatively associated with stunting ( $p=0.004)$. The prevalence of stunting was $56 \%$ among children who had not received vitamin $A$ supplement compared with $43 \%$ among those who had received the supplement. Ever receiving vitamin A supplement was also significantly negatively associated with underweight $(p=0.002)$, but not wasting.

Other factors with a significant association with stunting, underweight and wasting in the bivariate analysis level included perceived size at birth (for stunting and underweight), duration of breastfeeding (for wasting), morbidity from cough (marginal for underweight i.e. $\mathrm{p}=0.056$ ), BMI status of the mother (marginal for stunting, i.e. $p=0.051$ ), maternal education (for all three indices), urban or rural residence (for stunting and underweight), region of residence (for wasting and underweight), wealth index (for all three indices), source of drinking water (for stunting and underweight), type of toilet facility (for all three indices), and number of children under age 5 living in the household (for wasting and underweight) (Table 1).

\section{Association of Vitamin A Supplementation with Stunting and other Forms of Malnutrition}

As Table 2 shows, receiving vitamin A supplement remained significantly negatively associated with 
Table 1: Distribution of Stunting, Wasting and Underweight Among Children Age 24-35 Months by Vitamin A Supplementation and other Covariates at the Child, Maternal and Household Levels, $(\mathrm{N}=1,029)$, Kenya 2008

\begin{tabular}{|c|c|c|c|c|}
\hline & Stunting (\%) & Wasting (\%) & Underweight (\%) & Total $(\mathbf{N})$ \\
\hline \multicolumn{5}{|l|}{ Vitamin A supplementation } \\
\hline No & 55.9 & 7.4 & 28.6 & 222 \\
\hline $\mathrm{P}$-value & 0.004 & 0.537 & 0.002 & \\
\hline \multicolumn{5}{|l|}{ Child related characteristics } \\
\hline \multicolumn{5}{|l|}{ Sex of child } \\
\hline Female & 42.5 & 5.6 & 19.5 & 488 \\
\hline Male & 48.9 & 7.1 & 20.2 & 541 \\
\hline$p$-value & 0.071 & 0.452 & 0.830 & \\
\hline Large than average & 40.1 & 7.2 & 16.2 & 358 \\
\hline Smaller than average & 58.5 & 8.9 & 31.3 & 175 \\
\hline p-value & 0.007 & 0.236 & 0.006 & \\
\hline \multicolumn{5}{|l|}{ Birth order } \\
\hline $1 \mathrm{st}$ & 45.0 & 2.8 & 14.9 & 198 \\
\hline 2nd & 48.9 & 7.3 & 23.5 & 210 \\
\hline $3 r d$ & 42.1 & 4.5 & 17.6 & 207 \\
\hline 4th plus & 46.6 & 8.5 & 21.4 & 216 \\
\hline $24+$ & 41.6 & 5.5 & 19.7 & 357 \\
\hline Missing $^{1}$ & $N / A$ & $\mathrm{~N} / \mathrm{A}$ & $N / A$ & 10 \\
\hline$p$-value & 0.519 & 0.032 & 0.109 & \\
\hline \multicolumn{5}{|l|}{ Deworming status } \\
\hline Yes & 42.1 & 5.2 & 16.2 & 429 \\
\hline No & 48.6 & 7.2 & 22.4 & 600 \\
\hline$p$-value & 0.110 & 0.294 & 0.092 & \\
\hline \multicolumn{5}{|l|}{ Child morbidity $^{2}$} \\
\hline \multicolumn{5}{|l|}{ Acute diarrhoea } \\
\hline No & 44.3 & 6.3 & 19.8 & 857 \\
\hline Yes & 53.7 & 6.6 & 20.0 & 172 \\
\hline$p$-value & 0.064 & 0.913 & 0.963 & \\
\hline
\end{tabular}


(Table 1). Continued.

\begin{tabular}{|c|c|c|c|c|}
\hline & Stunting (\%) & Wasting (\%) & Underweight (\%) & Total $(\mathbf{N})$ \\
\hline \multicolumn{5}{|l|}{ Fever } \\
\hline Yes & 46.3 & 4.5 & 17.5 & 223 \\
\hline p-value & 0.915 & 0.233 & 0.424 & \\
\hline Yes & 46.4 & 5.8 & 24.8 & 273 \\
\hline p-value & 0.865 & 0.700 & 0.056 & \\
\hline \multicolumn{5}{|c|}{ Maternal characteristics Maternal age (at child's birth) } \\
\hline Under 20 & 51.2 & 3.4 & 19.3 & 154 \\
\hline 30 to 34 & 41.7 & 5.2 & 15.1 & 174 \\
\hline $35+$ & 42.0 & 5.9 & 10.8 & 135 \\
\hline p-value & 0.542 & 0.508 & 0.108 & \\
\hline \multicolumn{5}{|l|}{ BMI } \\
\hline Normal (BMI 18.5-24.9kg/m2) & 46.3 & 5.7 & 20 & 585 \\
\hline Low (BMI <18.5kg/m2) & 54.7 & 10.4 & 32.8 & 100 \\
\hline Overweight/obese $(\mathrm{BMI} \geq 25 \mathrm{~kg} / \mathrm{m} 2)$ & 33.5 & 6.2 & 7.8 & 145 \\
\hline Pregnant \& post-partum & 49.2 & 6.4 & 21.7 & 200 \\
\hline Secondary and above & 30.9 & 2.8 & 6.8 & 230 \\
\hline Primary & 50.8 & 6.2 & 23 & 684 \\
\hline No formal education & 46.5 & 14.2 & 27.3 & 115 \\
\hline$p$-value & 0.000 & 0.004 & 0.000 & \\
\hline \multicolumn{5}{|l|}{ Work status } \\
\hline Not working currently & 42.8 & 8.2 & 21.5 & 387 \\
\hline Currently working & 47.7 & 5.2 & 18.8 & 642 \\
\hline p-value & 0.205 & 0.129 & 0.500 & \\
\hline \multicolumn{5}{|l|}{ Household characteristics } \\
\hline \multicolumn{5}{|l|}{ Residence } \\
\hline Urban & 35.2 & 3.5 & 9.7 & 159 \\
\hline Rural & 47.8 & 6.9 & 21.7 & 870 \\
\hline $\mathrm{p}$-value & 0.027 & 0.185 & 0.001 & \\
\hline
\end{tabular}


(Table 1). Continued.

\begin{tabular}{|c|c|c|c|c|}
\hline & Stunting (\%) & Wasting (\%) & Underweight (\%) & Total (N) \\
\hline \multicolumn{5}{|l|}{ Region } \\
\hline Central & 41 & 4.8 & 11.8 & 90 \\
\hline Coast & 56.7 & 12.9 & 28.7 & 78 \\
\hline Nyanza & 43.8 & 5.5 & 19.3 & 187 \\
\hline Rift Valley & 46.3 & 9.1 & 24.7 & 256 \\
\hline Western & 35.8 & 2.1 & 11.2 & 159 \\
\hline North Eastern & 54.4 & 25 & 31.3 & 26 \\
\hline Lower & 51.9 & 3.2 & 27 & 239 \\
\hline Middle & 44.4 & 4.9 & 16.7 & 209 \\
\hline Higher & 37.5 & 7.3 & 14.0 & 160 \\
\hline Highest & 34.8 & 3.2 & 7.5 & 156 \\
\hline$p$-value & 0.012 & 0.016 & 0.000 & \\
\hline \multicolumn{5}{|c|}{ Source of drinking water ${ }^{3}$} \\
\hline Improved $^{4}$ & 39.6 & 5.8 & 16.5 & 574 \\
\hline Unimproved ${ }^{4}$ & 53.7 & 7.0 & 24.0 & 455 \\
\hline \multicolumn{5}{|l|}{ Toilet facilities $^{3}$} \\
\hline \multicolumn{5}{|c|}{ No. of U5 children in household ${ }^{6}$} \\
\hline 1 child & 38.9 & 3.4 & 12.6 & 338 \\
\hline 2 children & 45.7 & 6.7 & 25.2 & 446 \\
\hline 3 and above & 49.4 & 9.8 & 20.1 & 245 \\
\hline$p$-value & 0.181 & 0.031 & 0.004 & \\
\hline TOTAL & 45.9 & 6.4 & 19.8 & 1029 \\
\hline
\end{tabular}

Foot notes:

${ }^{1} \mathrm{~N} / \mathrm{A}=$ Not applicable; results for missing cases not shown because $\mathrm{n}$ is too small (unweighted $\mathrm{n}$ is less than 25).

${ }^{2}$ Self-reported morbidity from diarrhoea, or fever or cough in the last two weeks before the survey.

${ }^{3}$ Non-dejure defacto children in the household $(n=14)$ were assigned the water source and toilet facility of the household they were living in.

${ }^{4}$ Improved sources includes piped water sources, tubewell/borehole, protected wells and springs, and bottled water; Unimproved sources include all other sources such as surface water and rain water.

${ }^{5}$ Improved facility includes toilets with a flush to sewer, septic tank or to a pit latrine; no facility includes no facility/bush, flush to somewhere else; buckets , composting and hanging toilets.

${ }^{6}$ Non-dejure defacto children in the household $(n=14)$ were assigned the number of children under five years that live with their mother.

stunting even after adjusting for other co-risk factors at the child, maternal and household levels. The odds of stunting were $50 \%$ higher among children who had not received vitamin A supplement compared with children who had received the supplement $(p=0.038)$. Additionally, the odds of underweight status were $75 \%$ 
Table 2: Odds of Stunting, Wasting and Underweight for all Children Age 24-35 Months by Vitamin A Supplementation and other Covariates at the Child, Maternal and Household Levels $(N=1,029)$, Kenya 2008

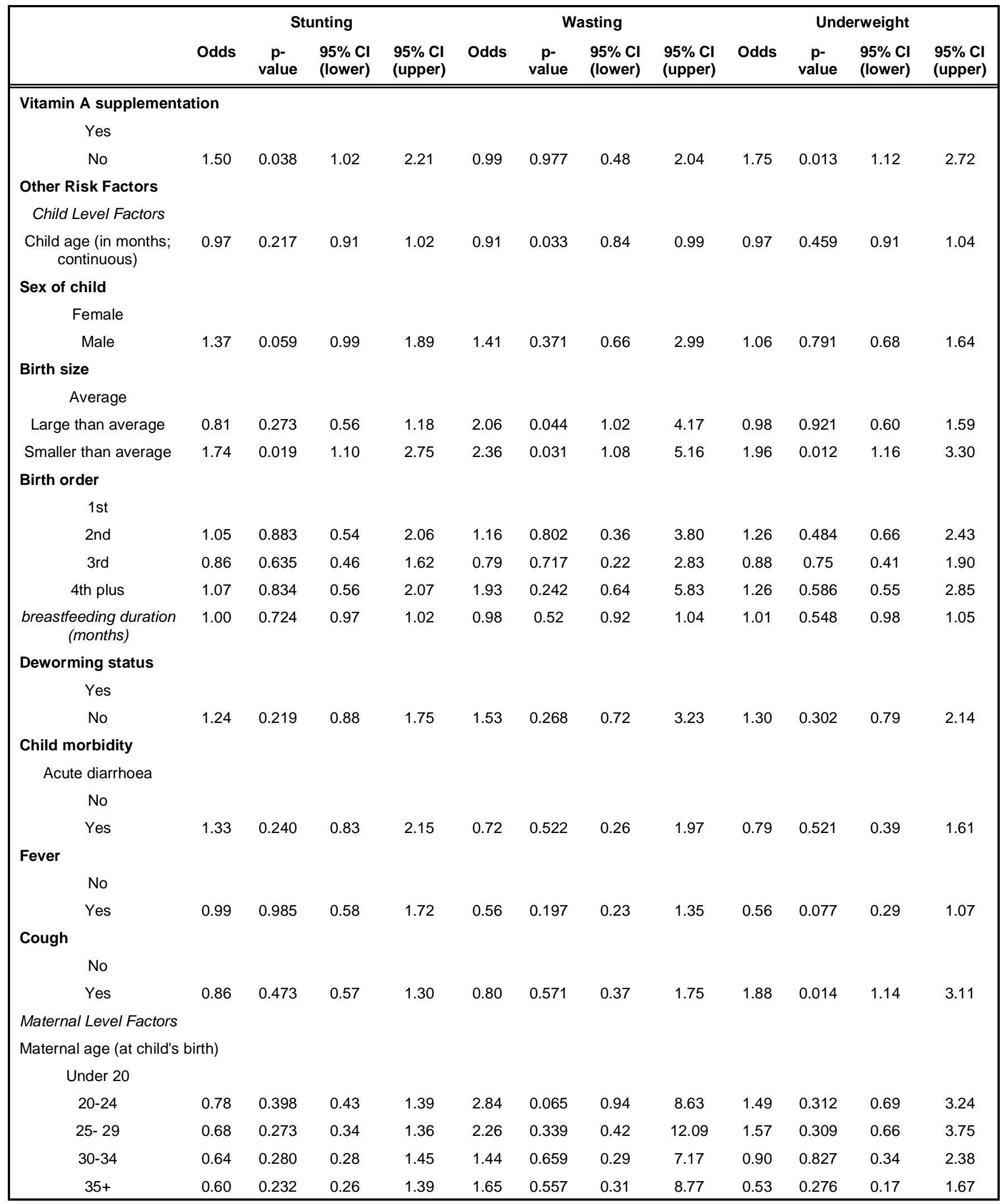


(Table 2). Continued

\begin{tabular}{|c|c|c|c|c|c|c|c|c|c|c|c|c|}
\hline & \multicolumn{4}{|c|}{ Stunting } & \multicolumn{4}{|c|}{ Wasting } & \multicolumn{4}{|c|}{ Underweight } \\
\hline & Odds & $\begin{array}{c}\mathrm{p}- \\
\text { value }\end{array}$ & $\begin{array}{l}95 \% \mathrm{Cl} \\
\text { (lower) }\end{array}$ & $\begin{array}{l}95 \% \mathrm{Cl} \\
\text { (upper) }\end{array}$ & Odds & $\begin{array}{c}\mathrm{p}- \\
\text { value }\end{array}$ & $\begin{array}{l}95 \% \mathrm{Cl} \\
\text { (lower) }\end{array}$ & $\begin{array}{l}95 \% \mathrm{Cl} \\
\text { (upper) }\end{array}$ & Odds & $\begin{array}{c}\mathrm{p}- \\
\text { value }\end{array}$ & $\begin{array}{l}95 \% \mathrm{Cl} \\
\text { (lower) }\end{array}$ & $\begin{array}{l}95 \% \mathrm{Cl} \\
\text { (upper) }\end{array}$ \\
\hline \multicolumn{13}{|c|}{$\begin{array}{c}\text { BMI } \\
\text { Normal (BMI 18.5-24.9kg/m2) }\end{array}$} \\
\hline Low $(\mathrm{BMI}<18.5 \mathrm{~kg} / \mathrm{m} 2)$ & 1.31 & 0.312 & 0.77 & 2.23 & 1.72 & 0.224 & 0.72 & 4.13 & 1.60 & 0.104 & 0.91 & 2.81 \\
\hline $\begin{array}{l}\text { Pregnant \& post- } \\
\text { partum }\end{array}$ & 1.15 & 0.555 & 0.72 & 1.86 & 1.15 & 0.800 & 0.40 & 3.30 & 0.94 & 0.781 & 0.59 & 1.49 \\
\hline \multicolumn{13}{|l|}{ Marital status } \\
\hline \multicolumn{13}{|l|}{ In union } \\
\hline Primary & 1.67 & 0.017 & 1.10 & 2.55 & 1.31 & 0.680 & 0.37 & 4.66 & 2.56 & 0.021 & 1.16 & 5.69 \\
\hline No formal education & 0.61 & 0.197 & 0.29 & 1.29 & 1.15 & 0.878 & 0.20 & 6.67 & 1.36 & 0.594 & 0.44 & 4.20 \\
\hline \multicolumn{13}{|l|}{ Work status } \\
\hline \multicolumn{13}{|l|}{ Not working currently } \\
\hline Currently working & 1.28 & 0.183 & 0.89 & 1.86 & 0.72 & 0.369 & 0.34 & 1.49 & 0.87 & 0.558 & 0.54 & 1.40 \\
\hline \multicolumn{13}{|l|}{ Household Level Factors } \\
\hline \multicolumn{13}{|l|}{ Residence } \\
\hline \multicolumn{13}{|l|}{ Urban } \\
\hline Nyanza & 0.29 & 0.010 & 0.12 & 0.74 & 0.90 & 0.94 & 0.07 & 12.40 & 0.42 & 0.253 & 0.10 & 1.86 \\
\hline Rift Valley & 0.38 & 0.033 & 0.16 & 0.92 & 1.70 & 0.677 & 0.14 & 20.59 & 0.59 & 0.471 & 0.14 & 2.46 \\
\hline Western & 0.27 & 0.006 & 0.10 & 0.69 & 0.32 & 0.410 & 0.02 & 4.77 & 0.22 & 0.052 & 0.05 & 1.01 \\
\hline North Eastern & 0.99 & 0.981 & 0.33 & 2.91 & 3.91 & 0.321 & 0.26 & 57.95 & 0.87 & 0.862 & 0.19 & 4.02 \\
\hline \multicolumn{13}{|l|}{ Wealth index } \\
\hline \multicolumn{13}{|l|}{ Lowest } \\
\hline Lower & 1.10 & 0.703 & 0.68 & 1.76 & 0.35 & 0.048 & 0.12 & 0.99 & 1.26 & 0.455 & 0.69 & 2.32 \\
\hline Middle & 1.13 & 0.685 & 0.63 & 2.03 & 0.79 & 0.682 & 0.25 & 2.49 & 0.96 & 0.915 & 0.44 & 2.08 \\
\hline Higher & 0.99 & 0.974 & 0.51 & 1.94 & 1.17 & 0.815 & 0.31 & 4.41 & 0.84 & 0.700 & 0.33 & 2.09 \\
\hline Highest & 0.88 & 0.774 & 0.37 & 2.10 & 0.71 & 0.731 & 0.10 & 4.97 & 0.43 & 0.152 & 0.13 & 1.37 \\
\hline \multicolumn{13}{|c|}{ Source of drinking water } \\
\hline Improved & & & & & & & & & & & & \\
\hline Unimproved & 1.42 & 0.046 & 1.01 & 2.02 & 0.80 & 0.539 & 0.39 & 1.64 & 0.99 & 0.962 & 0.65 & 1.51 \\
\hline
\end{tabular}


(Table 2). Continued.

\begin{tabular}{|c|c|c|c|c|c|c|c|c|c|c|c|c|}
\hline & \multicolumn{4}{|c|}{ Stunting } & \multicolumn{4}{|c|}{ Wasting } & \multicolumn{4}{|c|}{ Underweight } \\
\hline & Odds & $\begin{array}{c}\mathrm{p}- \\
\text { value }\end{array}$ & $\begin{array}{l}95 \% \mathrm{Cl} \\
\text { (lower) }\end{array}$ & $\begin{array}{l}95 \% \mathrm{Cl} \\
\text { (upper) }\end{array}$ & Odds & $\begin{array}{c}\mathrm{p}- \\
\text { value }\end{array}$ & $\begin{array}{l}95 \% \mathrm{Cl} \\
\text { (lower) }\end{array}$ & $\begin{array}{l}95 \% \mathrm{Cl} \\
\text { (upper) }\end{array}$ & Odds & $\begin{array}{c}\mathrm{p}- \\
\text { value }\end{array}$ & $\begin{array}{l}95 \% \mathrm{Cl} \\
\text { (lower) }\end{array}$ & $\begin{array}{l}95 \% \mathrm{Cl} \\
\text { (upper) }\end{array}$ \\
\hline \multicolumn{13}{|l|}{ Toilet facilities } \\
\hline \multicolumn{13}{|l|}{ Improved } \\
\hline unimproved & 1.27 & 0.260 & 0.84 & 1.92 & 1.81 & 0.317 & 0.56 & 5.81 & 1.26 & 0.546 & 0.59 & 2.69 \\
\hline No Facility & 1.80 & 0.048 & 1.01 & 3.22 & 1.85 & 0.286 & 0.59 & 5.78 & 1.81 & 0.148 & 0.81 & 4.06 \\
\hline $\begin{array}{l}\text { No. of U5 children in } \\
\text { household }\end{array}$ & 1.08 & 0.446 & 0.88 & 1.34 & 1.57 & 0.018 & 1.08 & 2.27 & 1.06 & 0.693 & 0.81 & 1.38 \\
\hline Total (N) & & 1029 & & & & 1029 & & & & 1029 & & \\
\hline
\end{tabular}

higher among children who had not received vitamin $\mathrm{A}$ supplement $(p=0.013)$.

\section{Co-Risk Factors of Malnutrition at the Child, Maternal and Household Levels}

As shown on Table 2, at the child level, after adjusting for other factors, age of the child, perceived size at birth and reported morbidity in the last two weeks were significantly associated with either stunting, underweight or wasting $(p<0.05)$. At the maternal level, only the education level of the mother was significantly associated with the nutritional status (stunting and underweight status, $\mathrm{p}<0.05$ ). At the household level, region of residence, source of drinking water, type of toilet facility used by the household, socio-economic status and number of children under the age of five living in the household were all significantly associated with either stunting, underweight or wasting $(p<0.05)$. However, these associations are beyond the focus of this study, and the inclusion of these co-risk factors in the models was mainly to control for their effects.

\section{DISCUSSION}

This study set out to determine if there is an association between vitamin $\mathrm{A}$ supplementation and stunting among young children age two - the age group with the highest level of stunting in Kenya, according to the 2008-09 KDHS [8]. The study shows that receiving vitamin $A$ supplement is significantly associated with children's growth. This suggests that vitamin A supplementation may be protective against stunting, or may reverse stunting $[16,22]$. This is important given the negative consequences of stunting at an early age and the fact that vitamin $A$ supplementation is a public health intervention in Kenya that is freely provided to children between the ages of six months and five years but that some children do not receive it.

The association between vitamin $A$ and child growth has been documented in observational studies [16, 22]. This association is linked to several mechanisms including the inverse relationship between vitamin A intake and incidence and severity of childhood infections, which may lead to growth faltering due to reduced nutritional intake, malabsorption of nutrients and increased nutrient expenditure during illness [23], and also the role of vitamin $A$ in cell differentiation and function, therefore showing biological plausibility [24].

Despite this established relationship between vitamin $\mathrm{A}$ and child growth, studies regarding vitamin $\mathrm{A}$ supplementation and growth in developing countries have found inconsistent results [16-18]. For example, in a randomized controlled study among pre-school Indonesian children age 6-48 months, Hadi et al. (2000) found that vitamin A supplementation improved linear growth. This effect was age specific, higher among children age 24 months or older compared with children under age 24 months. Additionally, this effect was higher among children who were not breastfed and those who were deficient of vitamin A [16]. Another study, however, in a randomized controlled trial in Northern Ghana found no significant association between vitamin A supplementation and linear growth of children age three or older, despite substantial reduction in severe morbidity and mortality in the same group [17]. Some studies have suggested that the inconsistencies are due to the effect of other factors in the environment, for example parasitic and respiratory infections, which may result in a lower effect on growth of infected children, and dietary vitamin A intake, also with a negative effect on the relationship between vitamin A supplementation and growth [14, 15]. Such variations in study findings suggest the importance of 
environmental context and hence the need for contextspecific studies on the association between vitamin $A$ supplementation and child growth.

The positive association between receiving vitamin A supplements and stunting observed in this study indicates that over and above any interactions between vitamin A supplementation and other factors affecting child morbidity and mortality, there may still be a net beneficial effect of providing vitatmin A supplementation. Continued government support of this important primary health intervention is essential, not only in addressing morbidity and mortality, but also in addressing malnutrition. This is particularly important with regards to stunting, given its short-term and longterm adverse effects, and which has persisted as a major public health concern in Kenya for many years $[8,25]$. It is unfortunate though that the coverage of vitamin A supplementation for the targeted age group (6-59 months) is very low at $30 \%$, with coverage being particularly low after the second year of life, and decreases with age [8]. The low coverage is despite the fact that vitamin $A$ is readily available in $\mathrm{MCH}$ facilities, i.e. $94 \%$ of facilities offering vaccinations also have vitamin $\mathrm{A}[26]$.

In this study our main focus was on the association between receiving vitamin A supplement and stunting. However, we also established an even stronger negative relationship between receiving vitamin $A$ supplement and underweight status. This relationship adds to the potential net benefit of vitamin A supplementation on growth among children in Kenya that should inform existing and future interventions on vitamin A supplementation. Additionally, we were able to establish other potential co-risk factors of undernutrition at the child, maternal and household levels. However, this was beyond the focus of this study, and these factors have been explained in other studies in Kenya [27, 28], and elsewhere [29-32].

Despite the importance of this study in determining the relationship between receiving vitamin $A$ supplements and undernutrition, we acknowledge possible endogeineity of receiving the supplement in that it may be influenced by other explanatory variables in the model including socio-economic status and mother's education, hence potential simultaneity bias. More complex analytic models beyond the scope of this study may be worthwhile in further explorations of this relationship. Additionally we are not able to establish a causal relationship, given the cross-sectional nature of the data. What we do know from the data, however, is that vitamin A supplements were given prior to the date when the outcome variables for stunting, wasting and underweight status were recorded. Further longitudinal studies to determine causal relationship are recommended. The Kenya demographic and health survey did not obtain data for all vitamin A supplementation doses. We therefore could not establish the dose-response relationship.

In summary, this study has demonstrated that vitamin A supplementation may be beneficial to the growth of young children, potentially either through protective mechanisms or through reversal of malnutrition [16, 22]. This is an important finding that should guide policy and programs regarding vitamin $A$ supplementation among children under age five through the primary health care system in Kenya and elsewhere in sub-Saharan Africa. However, further studies, as mentioned earlier are needed to better understand this relationship for more effective and targeted policies and programs.

\section{Policy Implications}

The prevalence of stunting for children aged less than five years, particularly those aged two years in Kenya is worrying. The low coverage of vitamin A supplementation, only at 30\% among children 6-59 months in the six months preceding the survey [8] is also of great concern, given that it is freely available for all children aged 6-59 months. The coverage of vitamin A supplementation among children aged three to five years is currently (since 2011) being maximized through provision at early child development (ECD) Centres. However, children aged two years are left out. This is because they usually have not joined the ECD Centres, and because they have generally completed the immunization schedule, they are hardly in contact with the primary health care facilities where they would be offered the supplements. There is need to find innovative and effective ways of reaching this group, and also those aged one year, who are also left out as most have also completed their immunization schedule by the age of one year. We recommend task sharing in vitamin A supplementation, allowing vitamin A supplementation to be given through the community strategy by community health workers who are in regular contact with children in the community.

\section{ACKNOWLEDGEMENTS}

This study was conducted through a DHS Further Analysis workshop organized and facilitated by ICF 
International and the National Council for Population and Development (NCPD), Kenya. We particularly acknowledge technical support from Sarah Staveteig and Sarah Bradley of ICF International. The initial manuscript was reviewed by Bryant Robey of ICF International and Geroge Kichamu of NCPD. We also acknowledge contribution of Margaret Kungu of NCPD in recoding of variables. Elizabeth Kimani-Murage is a Wellcome Trust Fellow.

\section{CONFLICT OF INTEREST}

To the best of our knowledge, there is no conflict of interest. Further, we would like to note that the views expressed by the authors do not necessarily reflect those of USAID.

\section{REFERENCES}

[1] Black RE, Allen LH, Bhutta ZA, Caulfield LE, de Onis M, Ezzati $\mathrm{M}$, et al. Maternal and child undernutrition: global and regional exposures and health consequences. Lancet 2008; 371(9608): 243-60.

\section{http://dx.doi.org/10.1016/S0140-6736(07)61690-0}

[2] Rice AL, Sacco L, Hyder A, Black RE. Malnutrition as an underlying cause of childhood deaths associated with infectious diseases in developing countries. Bull World Health Organ 2000; 78(10): 1207-21.

[3] World Health Organization (WHO). World Health report 2002: reducing risks, promoting healthy life. Geneva: WHO, 2002. Available from: http: //www.who.int/whr/2002/en/ whr02_en.pdf. Accessed August, 2012.

[4] Victora CG, Adair L, Fall C, Hallal PC, Martorell R, Richter L, et al. Maternal and child undernutrition: consequences for adult health and human capital. Lancet 2008; 371(9609): 340-57. http://dx.doi.org/10.1016/S0140-6736(07)61692-4

[5] Grantham-McGregor S, Cheung YB, Cueto S, Glewwe P, Richter L, Strupp B. Developmental potential in the first 5 years for children in developing countries. Lancet 2007; 369(9555): 60-70.

http://dx.doi.org/10.1016/S0140-6736(07)60032-4

[6] Oddy WH, Kendall GE, Blair E, De Klerk NH, Stanley FJ, Landau LI, et al. Breast feeding and cognitive development in childhood: a prospective birth cohort study. Paediatr Perinat Epidemiol 2003; 17(1): 81-90.

http://dx.doi.org/10.1046/j.1365-3016.2003.00464.x

[7] United Nations Standing Committee on Nutrition (SCN). Sixth report on the world nutrition situation: Progress in nutrition. Geneva: United Nations, 2010.

[8] Kenya National Bureau of Statistics (KNBS), ICF Macro. Kenya Demographic and Health Survey 2008-09: Calverton, Maryland: KNBS and ICF Macro; 2009.

[9] Imdad A, Sadiq K, Bhutta ZA. Evidence-based prevention of childhood malnutrition. Curr Opin Clin Nutr Metab Care 2011; 14(3): 276-85.

http://dx.doi.org/10.1097/MCO.0b013e328345364a

[10] Imdad A, Herzer K, Mayo-Wilson E, Yakoob MY, Bhutta ZA. Vitamin A supplementation for preventing morbidity and mortality in children from 6 months to 5 years of age. Cochrane Database Syst Rev 2010; (12): CD008524.

[11] Allen LH. Nutritional influences on linear growth: a general review. Eur J Clin Nutr 1994; 48(Suppl 1): S75-89.
[12] Umeta $M$, West CE, Verhoef $H$, Haidar J, Hautvast JG. Factors associated with stunting in infants aged 5-11 months in the Dodota-Sire District, rural Ethiopia. J Nutr 2003; 133(4): 1064-9.

[13] Rice AL, Stoltzfus RJ, de Francisco A, Chakraborty J, Kjolhede CL, Wahed MA. Maternal vitamin A or betacarotene supplementation in lactating bangladeshi women benefits mothers and infants but does not prevent subclinical deficiency. J Nutr 1999; 129(2): 356-65.

[14] Rosado JL, Caamano MC, Montoya YA, de Lourdes Solano $\mathrm{M}$, Santos $\mathrm{Jl}$, Long KZ. Interaction of zinc or vitamin $A$ supplementation and specific parasite infections on Mexican infants' growth: a randomized clinical trial. Eur J Clin Nutr 2009; 63(10): 1176-84. http://dx.doi.org/10.1038/ejcn.2009.53

[15] Hadi H, Dibley MJ, West KP, Jr. Complex interactions with infection and diet may explain seasonal growth responses to vitamin $\mathrm{A}$ in preschool aged Indonesian children. Eur $\mathrm{J}$ Clin Nutr 2004; 58(7): 990-9. http://dx.doi.org/10.1038/sj.ejcn.1601920

[16] Hadi H, Stoltzfus RJ, Dibley MJ, Moulton LH, West KP, Jr., Kjolhede CL, et al. Vitamin A supplementation selectively improves the linear growth of indonesian preschool children: results from a randomized controlled trial. Am J Clin Nutr 2000; 71(2): 507-13.

[17] Kirkwood BR, Ross DA, Arthur P, Morris SS, Dollimore N, Binka FN, et al. Effect of vitamin A supplementation on the growth of young children in northern Ghana. Am J Clin Nutr 1996; 63(5): 773-81.

[18] Ramakrishnan U, Latham MC, Abel R. Vitamin A supplementation does not improve growth of preschool children: a randomized, double-blind field trial in south India. J Nutr 1995; 125(2): 202-11.

[19] UNICEF. Strategies for improved nutrition of children and women in developing countries. A UNICEF policy peview. New York, NY: UNICEF, 1990. Available from: http: //www.ceecis.org/iodine/01_global/01_pl/01_01_other_1992 unicef.pdf. Accessed August, 2012.

[20] World Health Organization (WHO). WHO Anthro 2005, Beta version Feb 17th, 2006: Software for assessing growth and development of the world's children. Geneva: WHO, Available from: 2006. http: //www.who.int/childgrowth/ software/en/. Accessed Feb, 2012.

[21] Filmer D, Pritchett LH. Estimating wealth effects without expenditure data--or tears: an application to educational enrollments in states of India. Demography 2001; 38(1): 115 32

[22] Sedgh G, Herrera MG, Nestel P, el Amin A, Fawzi WW. Dietary vitamin A intake and nondietary factors are associated with reversal of stunting in children. J Nutr 2000; 130(10): 2520-6.

[23] Underwood BA, Arthur P. The contribution of vitamin A to public health. FASEB J 1996; 10(9): 1040-8.

[24] De Luca LM. Retinoids and their receptors in differentiation, embryogenesis, and neoplasia. FASEB J 1991; 5(14): 2924 33.

[25] CBS Kenya MoHMK, ORC Macro. Kenya Demographic and Health Survey 2003: Key Findings. Calverton, Maryland, USA: CBS, MOH and ORC Macro 2004.

[26] National Coordinating Agency for Population and Development (NCAPD) [Kenya], Ministry of Medical Services (MOMS) [Kenya], Ministry of Public Health and Sanitation (MOPHS) [Kenya], Kenya National Bureau of Statistics (KNBS) [Kenya], Macro. I. Kenya Service Provision Assessment Survey 2010. Nairobi, Kenya: National Coordinating Agency for Population and Development, Ministry of Medical Services, Ministry of Public Health and Sanitation, Kenya National Bureau of atistics, and ICF Macro 2011. 
[27] Gewa CA, Yandell N. Undernutrition among Kenyan children: contribution of child, maternal and household factors. Public Health Nutr 23: 1-10.

[28] Kabubo-Mariara J, Ndenge GK, Mwabu DK. Determinants of Children's Nutritional Status in Kenya: Evidence from Demographic and Health Surveys. J Afr Econ 2008.

[29] Griffiths P, Madise N, Whitworth A, Matthews Z. A tale of two continents: a multilevel comparison of the determinants of child nutritional status from selected African and Indian regions. Health Place 2004; 10(2): 183-99.

http://dx.doi.org/10.1016/j.healthplace.2003.07.001

[30] Hien NN, Kam S. Nutritional status and the characteristics related to malnutrition in children under five years of age in
Nghean, Vietnam. J Prev Med Public Health 2008; 41(4): 232-40.

http://dx.doi.org/10.3961/jpmph.2008.41.4.232

[31] Frost MB, Forste R, Haas DW. Maternal education and child nutritional status in Bolivia: finding the links. Soc Sci Med 2005; 60(2): 395-407.

http://dx.doi.org/10.1016/j.socscimed.2004.05.010

[32] Pongou R, Ezzati M, Salomon JA. Household and community socioeconomic and environmental determinants of child nutritional status in Cameroon. BMC Public Health 2006; 6: 98.

http://dx.doi.org/10.1186/1471-2458-6-98

Received on 03-09-2012

Accepted on 20-12-2012

Published on 31-12-2012

http://dx.doi.org/10.6000/1929-4247.2012.01.02.5

(c) 2012 Kimani-Murage et al.; Licensee Lifescience Global.

This is an open access article licensed under the terms of the Creative Commons Attribution Non-Commercial License (http://creativecommons.org/licenses/by-nc/3.0/) which permits unrestricted, non-commercial use, distribution and reproduction in any medium, provided the work is properly cited. 